\title{
Communication Skills Training
}

National Cancer Institute

\section{Source}

National Cancer Institute. Communication Skills Training. NCI Thesaurus. Code C116531.

The attempt to improve the techniques and tactics an individual uses to communicate. 